\title{
Effectiveness of Thermal Stimulation of Superplasticizers on Fresh Properties of Cement Mortar
}

\author{
Mizuki Takigawa $^{1} \cdot$ Hiroshi Nemoto $^{2} \cdot$ Shin-ichiro Hashimoto ${ }^{3} \cdot$ Shigeyuki Date $^{4}(\mathbb{C}$
}

Received: 25 March 2021 / Accepted: 25 October 2021 / Published online: 9 November 2021

(c) The Author(s) 2021

\begin{abstract}
Polycarboxylic acid-based superplasticizers are used in various types of concrete work. Wide variations in environmental temperatures are known to affect how well chemical admixtures perform as superplasticizers, influencing the properties of the concrete. However, little has been reported on changes in performance caused by thermal variations. Previous studies have reported that heating superplasticizers change the polymer structure, improving and sustaining cement particles' dispersibility. Moreover, the improved fluidity from thermal stimulation is not temporary. The effect has been observed to remain for about seven days, with the residual characteristics differing depending on the superplasticizers used. Therefore this study evaluates mortar stiffness when using thermally stimulated superplasticizers and evaluates how the stimulation affects construction performance using measures such as the flow and rheological properties (plastic viscosity) of fresh mortar, vane shear tests, blade viscometer tests, and mortar vibration box tests. Mortar's fluidity was found to improve by about $25 \%$ when using thermally stimulated additives, with plastic viscosity dropping by up to $45 \%$ and the stress likely to be needed for pumping also being reduced by about $16 \%$. Filling speed was also found to increase by about $26 \%$. Thus, thermal stimulation improves mortar and concrete construction performance, and it may be possible in the future to carry out the construction with fewer workers utilizing this technology's benefits. The study indicates a need for further investigation of how thermal stimulation affects polymer molecules' adsorption efficiency with cement to elucidate the mechanism at full scale and propose ways to adopt thermal stimulation at actual construction sites.
\end{abstract}

Keywords Thermal stimulation $\cdot$ Superplasticizers $\cdot$ Mortar flow $\cdot$ Construction performance

\section{Introduction}

Superplasticizers, such as high-performance water-reducing admixtures and air-entraining agents, are used widely because they are effective in both reducing water requirements and retaining fluidity. Research and development of these products have proceeded for over twenty years (Morita

Shigeyuki Date

sdat@tokai-u.jp

1 Graduate School of Science and Technology, Tokai University, Hiratsuka, Kanagawa, Japan

2 Civil Engineering Group of Shimizu Corporation, Tokyo, Japan

3 Department of Architecture, Faculty of Creative Engineering, Chiba Institute of Technology, Narashino, Chiba, Japan

4 Department of Civil Engineering, Graduate School of Science and Technology, Tokai University, Hiratsuka, Kanagawa, Japan and Ohta 1994; Ohta 2005; Lucia et al. 2010, 2011). Adding small amounts of polycarboxylic acid superplasticizers, which are mainly used in construction along with other types of superplasticizers, can generally produce the required fluidity. Previous research has shown that the molecular structure can be easily changed and that the additives improve powder particles' dispersal as well as help the mix retain fluidity (Sugamata et al. 2000; Ohta 1997; Uchikawa et al. $1997 \mathrm{a}, \mathrm{b})$. The fluidity of mortar and concrete achievable when using these superplasticizers has been observed to vary depending on the powder used, the ambient temperature, and the mixing method (Haga et al. 1999; Ohta and Uomoto 1997; Papayianni et al. 2005).

Previous studies have shown that the performance of dispersants based on comb-like copolymers, such as polycarboxylic acid-based superplasticizers, depends on the length and sparsity of the side chains of the copolymers (Ohta 1997; Robert et al. 2009; Qianping et al. 2009; Hamada et al. 2000; Bache 1981). It has also been confirmed that by 
changing the balance of the molecular backbone, such as its molecular weight, molecular weight distribution, graft chain length, and the composition ratio of the components, waterreducing agents with different dispersibilities can be synthesized. Their active mechanisms and the degree to which they adsorb with cement particles can also be affected (Qianping et al. 2009; Sakai et al. 2003). For example, in a study by Süleyman Özen et al., the effect of changes in the length of both the main and side chains of a polycarboxylic acid superplasticizer on the flowability of cement pastes and mortars was confirmed by mini-slump tests and analysis using total organic carbon (Özen et al. 2020). The results confirmed that changes in the length of the superplasticizer's main and side chains affected how long the mortar's flowability could be maintained. Their results also suggest that longer and more entangled main and side chains reduce adsorption capacity with cement particles.

To date, DLVO theory has been used to discuss superplasticizers' active mechanisms (Lagaly 1977; Tanaka et al. 1996). However, polycarboxylic acid superplasticizers' zeta potential on the surface of cement particles is lower than that of polymers used as raw materials for other superplasticizers, yet they exhibit high dispersibility. The mechanism by which these superplasticizers disperse cement particles is explained by steric hindrance via repulsive forces of polymer molecules in the polycarboxylic acid superplasticizers (Sugiyama et al. 2000; Yamada et al. 2001). In addition to this electro-repulsive force, it has been proposed that dispersion is stabilized by the steric effect of the adsorbed polymer layer. In order to secure and maintain flowability, many products have been developed that contain several types of polymers that cause different dispersion effects (Sugiyama et al. 2000; Mackor 1951; Fischer 1958). It is well known that the flow of concrete using superplasticizers fluctuates with changes in environmental temperature (Uchikawa et al. 1997a, b; Kato et al. 1999). For example, Jolicoeur et al. (1997) used different binders and superplasticizers to study the effect of environmental temperature change on the workability of concrete and confirmed its effect on rheological properties by measuring plastic viscosity using a mini-slump test and viscometer. Petit et al. (2005) also investigated the effect of environmental temperature change on yield value using a rotational viscometer. These results confirmed that the rheological properties and yield values of mortar varied depending on changes in environmental temperature, and that slump loss was also affected.

It is less widely known that concrete fluidity can be improved by heating superplasticizers. Most previous studies have focused on changes in environmental temperature, not on intentional processes of heating and maintaining the high temperature of the superplasticizer.

One previous study formulated a hypothesis that superplasticizers are stimulated by heat, which improves the three-dimensional area of the polymer and the adsorption area of the cement (hereinafter "thermal stimulation") (Takigawa et al. 2018, 2019). Based on this hypothesis, a superplasticizer was heated at $40{ }^{\circ} \mathrm{C}$ to $60^{\circ} \mathrm{C}$ for $0.5 \mathrm{~h}$ or $24 \mathrm{~h}$. Using mortar flow tests and dynamic light scattering (DLS), the authors showed a change in the fluidity of the mortar and the apparent three-dimensional area of the polymer. The results confirmed that mortar fluidity improves because the apparent molecular size increases when the superplasticizer is thermally stimulated, with higher heating temperature and longer heating time enhancing the effect.

In addition, although there was concern that there may be a reactive decrease in the mortar's slump keeping performance when initial flowability improved, the study showed that there was a little untoward effect.

However, whether the endpoints are causally linked to construction performance measures such as filling and passaging performance has not been confirmed, because in previous studies, only mortar's fresh properties and slump keeping characteristics have been investigated. Further research on the effects of thermal stimulation is expected to lead to improvements in construction performance. Previous studies have shown that several approaches are necessary to evaluate the dispersion effectiveness of polycarboxylic acid-based superplasticizers. It is essential to evaluate rheological properties because they are directly related to actual construction performance (Mezger 2006; Kirby and Lewis 2008).

This study quantifies the performance of mortar containing thermally stimulated plasticizers under construction conditions, especially its plastic viscosity, stiffness, and filling performance with and without vibration.

\section{Methodology}

\subsection{Materials}

The materials used are shown in Table 1. Two kinds of superplasticizers were tested in this study, a high-range water-reducing agent mainly used for precast concrete (hereinafter "PCa-type") and a high-range water-reducing

Table 1 Materials used

\begin{tabular}{lll}
\hline Material & Symbol & Properties \\
\hline Cement & $\mathrm{C}$ & $\begin{array}{l}\text { Ordinary Portland cement } \\
\text { Density: } 3.16 \mathrm{~g} / \mathrm{cm}^{3}\end{array}$ \\
Fine aggregate & $\mathrm{S}$ & $\begin{array}{l}\text { River sand from Kanagawa } \\
\text { Density: } 2.69 \% \\
\text { Water absorptivity: } 1.49 \%\end{array}$ \\
Superplasticizers & PCa & $\begin{array}{l}\text { High range water reducing agent } \\
\text { High range water reducing agent } \\
\end{array}$ \\
& RMC & AE-Type \\
\hline
\end{tabular}


AE-type agent mainly used for ready mix concrete (hereinafter "RMC-type"). Both polymers are acrylic acid-based polycarboxylic acids. The structural difference between them is that the PCa-type has a higher density of carboxyl groups in its structure, while the RMC-type has a higher density of ethylene oxide side chains. The synthesis of these polymers is done by radical polymerization, and during polymerization, the polymer is heated to a temperature of $40{ }^{\circ} \mathrm{C}$ or higher.

\subsection{Heating Method}

In order to prevent the vaporization of the superplasticizer during heating, it was encapsulated in a small polypropylene bottle and warmed in hot water. The superplasticizer was heated to $60^{\circ} \mathrm{C}\left( \pm 1^{\circ} \mathrm{C}\right)$ over $24 \mathrm{~h}$ as in previous studies (Takigawa et al. 2018, 2019). The rate of temperature increase of the sample was approximately $1.5^{\circ} \mathrm{C} / \mathrm{min}$.

\subsection{Experimental Conditions}

The change in mortar flowability was confirmed by flow tests under all conditions to verify the effect of thermal stimulation on fluidity. Flow tests were conducted without tamping to flow values of $120 \pm 10 \mathrm{~mm}$ for each amount of superplasticizer added and each mixing proportion without thermal stimulation. In this study, similar experiments were repeated for all data, and reproducibility was carefully confirmed. Measurement error over all the experimental data was about $\pm 20 \mathrm{~mm}$ both with and without thermal stimulation.

\subsection{Mixing Procedure}

The mixing procedure is shown in Fig. 1 and the symbols used in Fig. 1 are defined in Table 1. Mixing in this study was performed using a 20 L Hobart mixer. Mixing with and without thermal stimulation was done in the same way. Ambient conditions during mixing and testing were $20{ }^{\circ} \mathrm{C}$ with $60 \%$ relative humidity. As shown in Fig. 1, superplasticizers were added to the mixing water immediately before mixing. The temperature of the mixing water was measured immediately after the addition, and it remained at about $20{ }^{\circ} \mathrm{C}$, indicating that the heated superplasticizers quickly cooled when added to the mixing water.

\subsection{Experimental Methods}

\subsubsection{Mortar Flow}

The fresh mortar was tested in accordance with JIS R 5201 "Physical testing methods for cement". Figures 2 and 3 show the apparatus for the flow test specified by the Japanese Standards Association (2015) and the conditions during the experiment. As shown in Fig. 2, the flow test apparatus, which conforms to JIS R 5201, consisted of a flow table having a diameter of $300 \mathrm{~mm}$ and a $10 \mathrm{~mm}$ free fall distance from top to bottom, and a flow cone with an upper inner diameter of $70 \mathrm{~mm}$, a lower inner diameter of $100 \mathrm{~mm}$, and a height of $60 \mathrm{~mm}$. The flow cone was placed in the center of the flow table, and the mortar was placed in two layers. After the first and second layers were placed, the mortar was immediately compacted 15 times with a stick $(20 \mathrm{~mm}$ in diameter, $200 \mathrm{~mm}$ in length). After compaction, the surface was leveled parallel to the flow table, the flow cone was removed, and the 0 tamp flow was measured (hereinafter "without tamping flow value"). Then the handle was turned once per second 15 times and the 15 tamps flow value (hereinafter "flow value") was measured. The without tamping and with tamping flow values were measured twice for each test, and the average value was used as the flow value. Three or more repetitions were used for all flow tests.

\subsubsection{Mortar Stiffness}

The stiffness of the mortar was evaluated using a vane shear test (Nemoto et al. 2020). Here, stiffness is defined as the decrease in flowability of fresh mortar without vibration. The vane shear test was used in this study to compare the magnitude of stress needed to cause mortar and concrete to re-flow once the flow has stopped. A schematic of the vane shear test is shown in Fig. 4, while a photo of the actual experimental equipment is shown in Fig. 5. An $8.2 \mathrm{~L}$ of mortar was placed in the cylindrical container $(\varnothing 10 \times 27 \mathrm{~cm})$, and the container was set in a table vibrator used for cement strength testing. The steel-bladed vane was inserted into the mortar and the maximum torque value $(M$-max) was obtained by rotating the shaft manually. The maximum shear stress was calculated using an expression for $M$-max obtained from

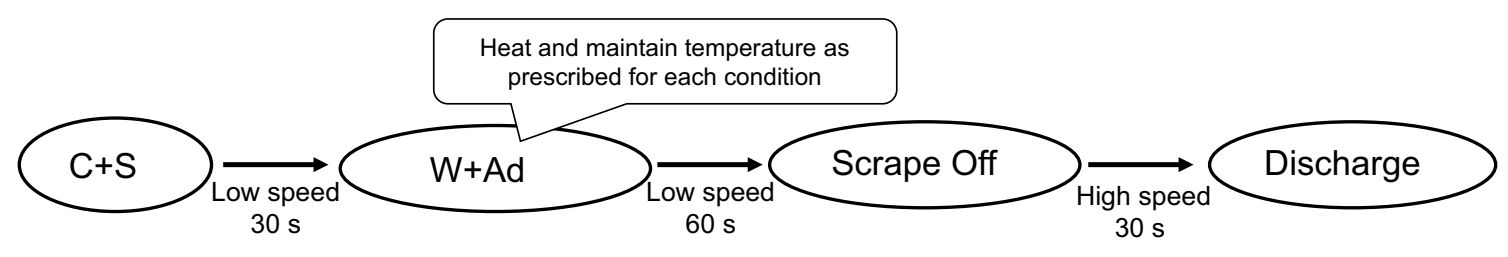

Fig. 1 Mixing procedure 


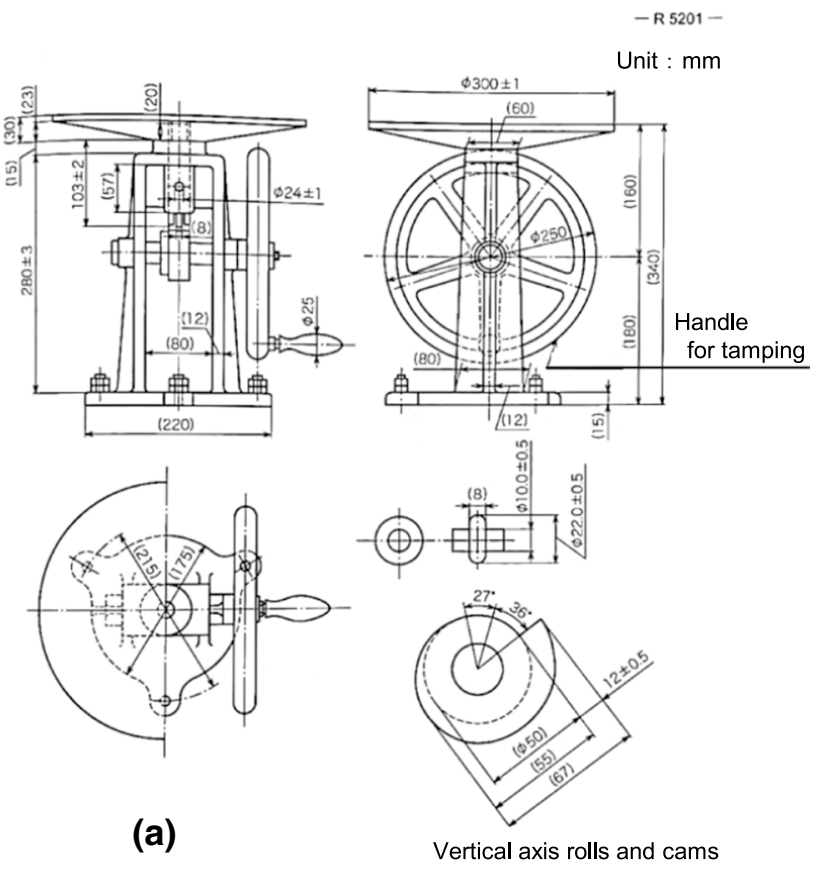

- R $5201-$
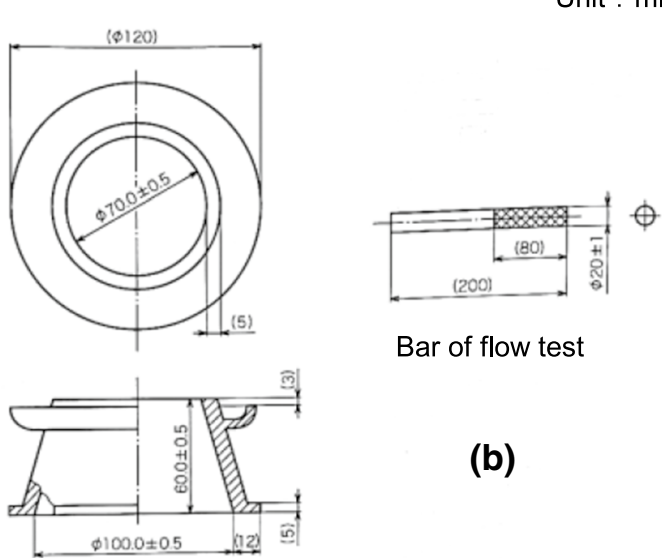

Bar of flow test

(b)

Flow cone

"( )" indicates a reference value.

Fig. 2 Mortar flow apparatus schematic a Flow table, b Flow cone (Japanese Standards Association 2015)

the Cading equation (Shibata. 1967). In this study, the vane was rotated manually at an assumed angular rate of $6 \mathrm{rpm}$, the shaft was $8 \mathrm{~mm}$ in diameter, the vane width was $30 \mathrm{~mm}$, and the vane height was $60 \mathrm{~mm}$.

$\tau_{v}=\frac{M_{\max }}{\pi\left(\frac{D^{2} H}{2}+\frac{D^{3}}{6}\right)}$

$M$-max: Maximum torque value, $D$ Vane width (mm), $H$ Vane height $(\mathrm{mm})$.

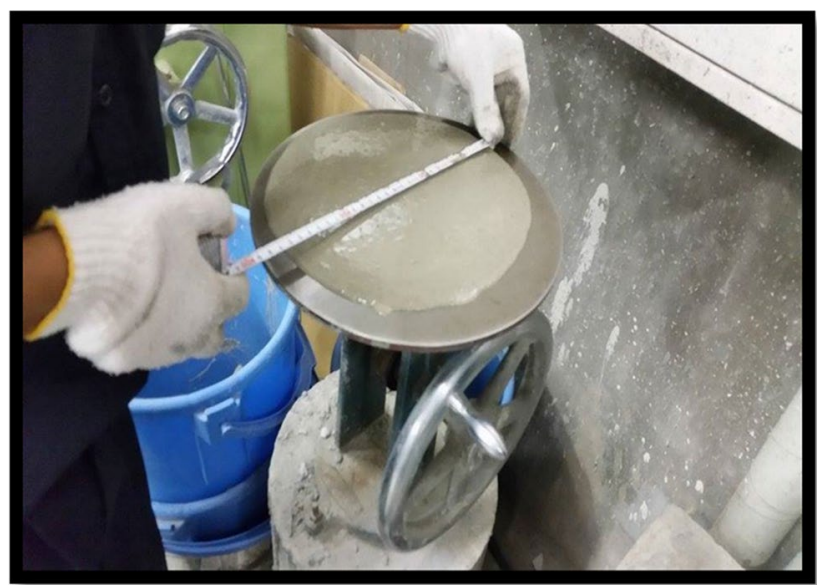

Fig. 3 Mortar flow photo

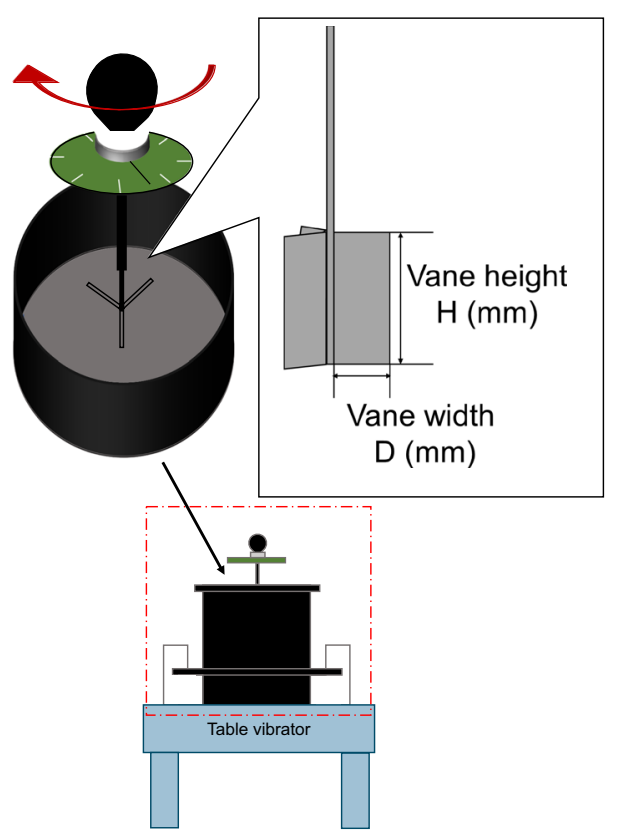

Fig. 4 Vane shear test schematic

\subsubsection{Plastic Viscosity of Mortar}

To measure the effect of thermal stimulation on the rheological properties of mortar, a blade viscometer was used to assess plastic viscosity (Takehisa et al. 2018; Muroga et al. 2000). A schematic of the blade viscometer is shown in Fig. 6 and a photo of the actual experimental equipment is shown in Fig. 7. The blade viscometer was used in this study to evaluate the flowability of mortar and concrete under static and vibratory conditions to model conditions at actual construction sites where pumping is used. As in the vane shear test, $8.2 \mathrm{~L}$ of mortar was loaded into the cylindrical container $(\varnothing 10 \times 27 \mathrm{~cm})$, and the container was set in a 


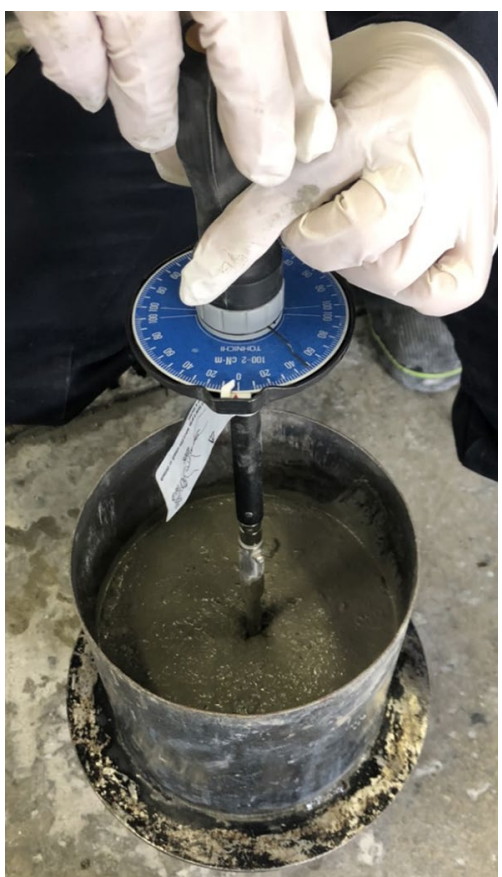

Fig. 5 Vane shear test photo

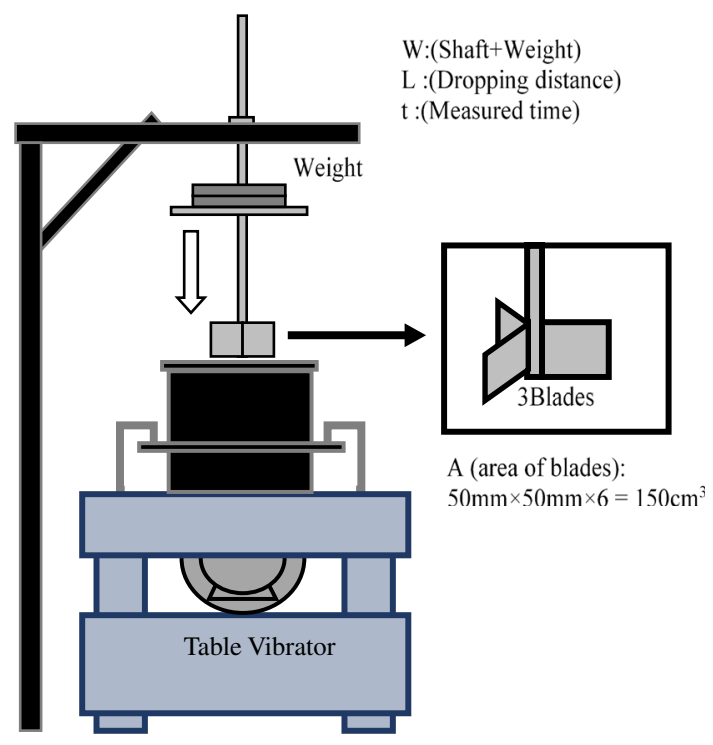

Fig. 6 Blade viscometer schematic

table vibrator used for cement strength testing. As in Fig. 4, a weighted steel rod with three thin steel blades sank into the fresh mortar under its own weight. The apparent plastic viscosity is determined from the shear resistance when the blades move at a constant speed in the mortar during flow using the relationship between the settling velocity $(\fallingdotseq$ shear strain rate) and material weight ( $\fallingdotseq$ shear stress). This differs when the mortar is under static and vibrating conditions. In

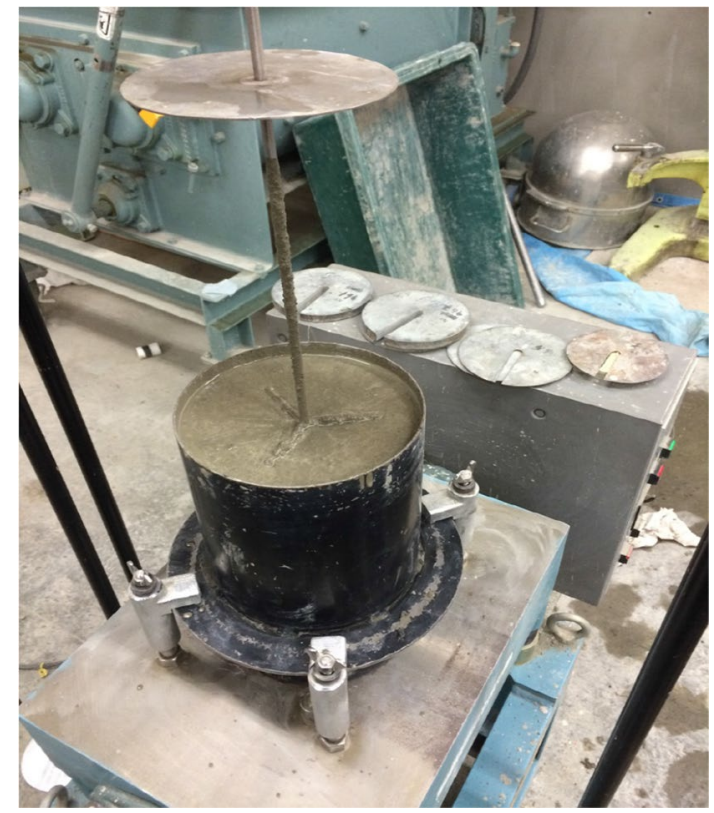

Fig. 7 Blade viscometer photo

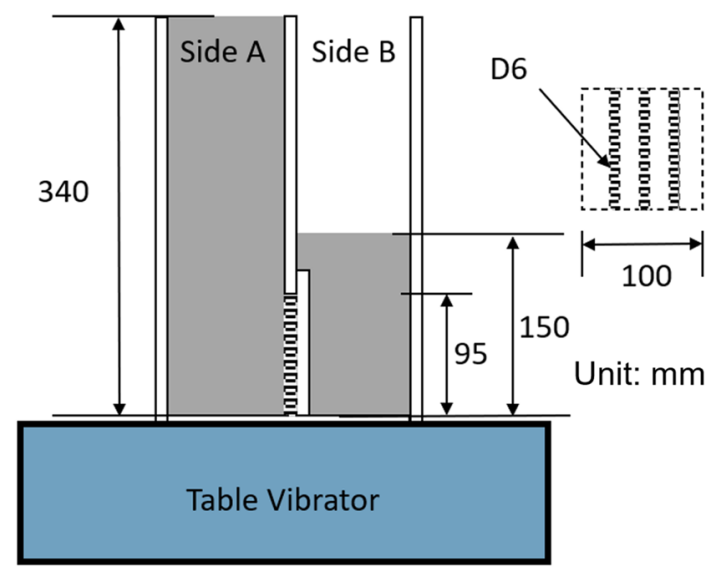

Fig. 8 Mortar vibration box test schematic

this study, the acting buoyant force while the blades dropped into the fresh mortar and the shear area were assumed to be constant, as the blades were completely submerged in the fresh mortar when the measurement started. A table vibrator with a frequency of $40 \mathrm{~Hz}$ (amplitude: $1 \mathrm{~mm}$ ) was used for measurements under vibration, similar to the procedure in a previous study (Takehisa et al. 2018).

\subsubsection{Mortar Fluidity Change Under Vibration}

This evaluation was made using a mortar vibration box test to confirm the effect of thermal stimulation on the mortar's filling properties (Muroga et al. 2000). A schematic of the mortar vibration box test is shown in Fig. 8, and a photo of 
the actual experimental equipment is shown in Fig. 9. This test apparatus was $1 / 2$ the size of the box-type container used for high-fluidity concrete (JSCE-F511). The bottom surface of the mortar vibration box test device was secured on a table vibrator, and a fixed plate was attached such that it would not move. To test the mortar's pass-through between obstacles, R2 (the gap between the steel parts was about $60-200 \mathrm{~mm}$, and the unit volume weight of the steel was $100-350 \mathrm{~kg} / \mathrm{m}^{3}$ ) was simulated, and three D6 deformed reinforcing bars were set at equal intervals in a $100 \mathrm{~mm}$ gap $(25 \mathrm{~mm} \times 4)$. For the mortar vibration box test, space A was divided into three layers and filled with mortar using a stick. After smoothing the upper surface of space A and letting it stand for $1 \mathrm{~min}$, the table vibrator was started simultaneously with the partition between the spaces being pulled up. The points at which the filling heights of space B reached $95 \mathrm{~mm}$ and $150 \mathrm{~mm}$ were visually confirmed, and the elapsed times from the start of vibration were measured. The speed of movement was calculated from the time required for the filled height to change from 95 to $150 \mathrm{~mm}$. This was used as the gap-passing speed (hereinafter "V-pass"). The vibration at the time of excitation was set to $40 \mathrm{~Hz}$ (amplitude: $1 \mathrm{~mm}$ ), which is the same as in the blade viscometer test.

\section{Results and Discussion}

\subsection{Effect of Thermal Stimulation on Plastic Viscosity and Mortar Stiffness Without Tamping}

In a previous study, the slump life of mortar having a variety of agents added was evaluated without tamping (Takigawa et al. 2019). These included the following additives: $\mathrm{PCa}, \mathrm{RMC}$, high-range water-reducing agents with high

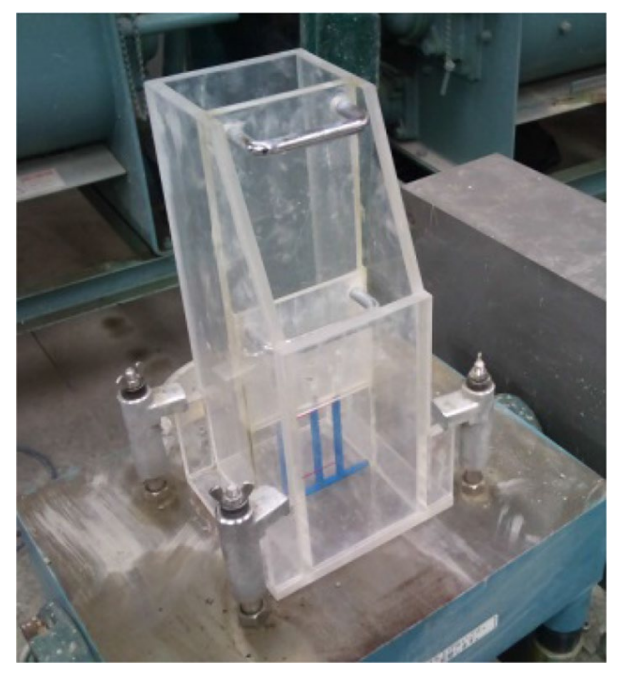

Fig. 9 Mortar vibration box test photo dispersion (hereinafter "DP-type"), and high-slump-keeping high-range water-reducing agents (hereinafter "SK-type"). All the superplasticizers contained polycarboxylic acid ether-based polymers. PCa- and RMC-type superplasticizers could be produced by blending SK- and DP-type additives. The mixing ratio of the SK-type polymer tends to be higher in RMC-type plasticizers than in PCa-type ones. The results are shown in Figs. 10 and 11. These results confirm that even when thermal stimulation improves fluidity through enhanced initial dispersion, slump-keeping performance can be maintained. This was speculated to be linked to changes in the polymer's molecular structure due to heat stimulation. The results for plastic viscosity and stiffness under static conditions are shown in Figs. 12 and 13. These results confirm that even when thermal stimulation improves fluidity through enhanced initial dispersion, slump-keeping performance can be maintained. This was speculated to be linked to changes in the polymer's molecular structure due to heat stimulation. The results for plastic viscosity and stiffness under static conditions are shown in Figs. 12 and 13.

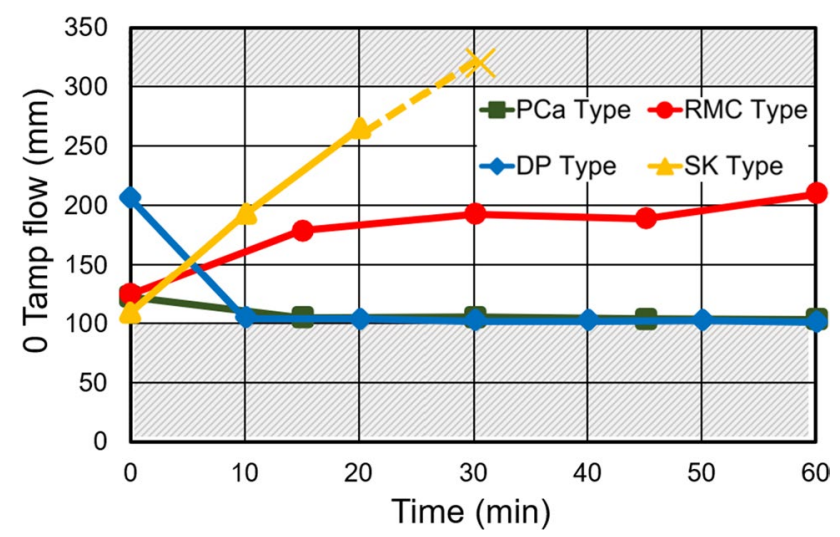

Fig. 10 Slump life of 0 tamp mortar flow (without heating) (Takigawa et al. 2019)

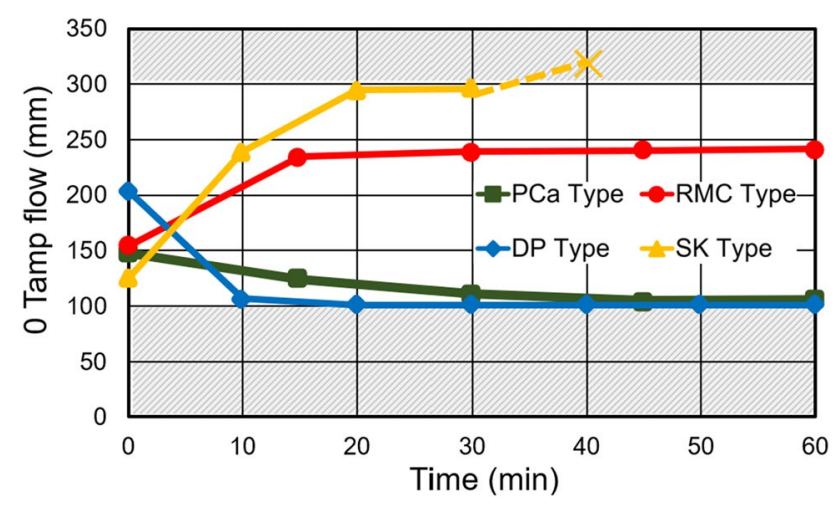

Fig. 11 Slump life of 0 tamp mortar flow (heated: $60{ }^{\circ} \mathrm{C}, 24 \mathrm{~h}$ ) (Takigawa et al. 2019) 


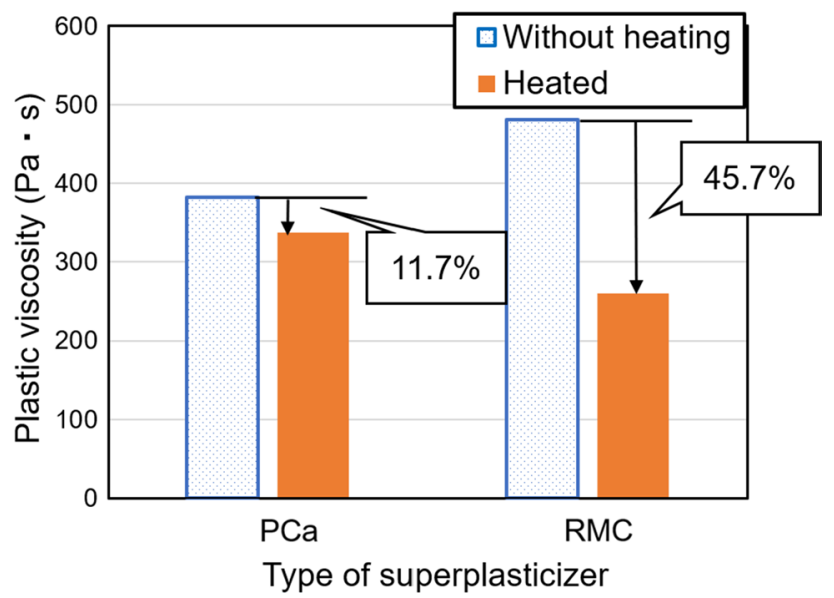

Fig. 12 Plastic viscosity (without vibration)

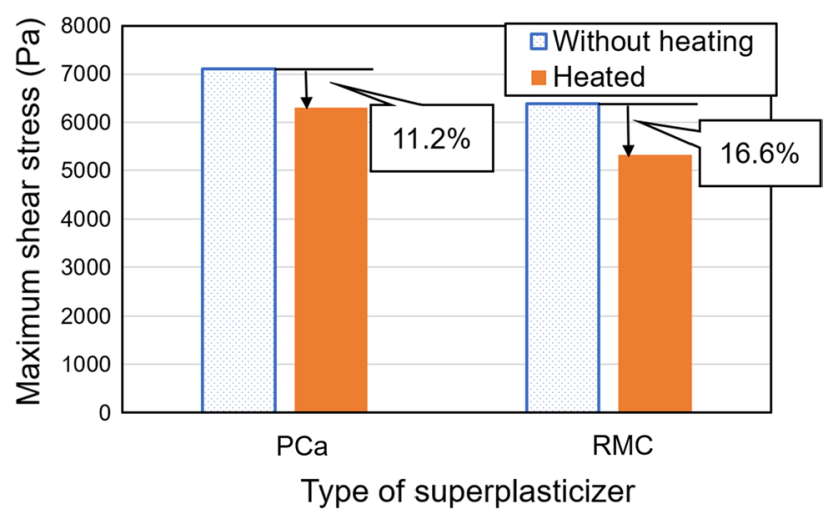

Fig. 13 Stiffness (without vibration)

As the figures show, thermal stimulation reduces the plastic viscosity by $12 \%$ for the PCa-type and about $45 \%$ for the RMC-type additive. Moreover, stiffness decreased by about $11 \%$ for the PCa-type and about $16 \%$ for the RMC-type additive. A recent study reported that the stiffness of mortar and concrete is caused by the agglomeration of cement particles during initial hydration (Nemoto et al 2020). The degree of agglomeration of cement particles is one indicator of the fresh properties of mortar and concrete. In particular, it is widely known that when cement particles easily agglomerate, the dispersibility of the cement is reduced, which changes the hydration reaction rate and microstructure formation of the cement and affects its performance after hardening. Previous studies have shown that polycarboxylic acid-based superplasticizers create weaker intermolecular forces due to the effect of steric hindrance and thus have better cement dispersibility than other raw polymer superplasticizers (Robert 2004). For example, Yuta Ohtsuka et al. used a stress-controlled rotational viscometer to measure temporal changes in the flowability and viscosity of concrete. When comparing polycarboxylic acid superplasticizers to naphthalene sulfonic acid ones, they found that polycarboxylic acid superplasticizers maintain better flowability and workability due to differences in molecular structure (Ohtsuka et al. 2015). Jacek Gołaszewski et al. used naphthalene sulfonic acid superplasticizers and polycarboxylic acid superplasticizers and confirmed their effect on the rheological properties of concrete using a PC rheometer. They found that the naphthalene sulfonic acid superplasticizers increased the yield values and decreased workability (Jacek and Janusz 2004). In another study, Chandra and Björnström (2002) confirmed that naphthalene sulfonate and melanin sulfonate superplasticizers showed a more significant temporal change in slump loss than polycarboxylic acid superplasticizers. This is because naphthalene sulfonic acid has a straight-chain-type molecular structure and has a different active mechanism than polycarboxylic acid-based superplasticizers (Ohta 1997; Sugiyama et al. 2000). The relevant extant studies (Takigawa et al. 2018, 2019; Nemoto et al. 2020; Robert 2004; Ohtsuka et al. 2015; Jacek and Janusz 2004; Chandra and Björnström 2002) show that polycarboxylic acid superplasticizers hinder agglomeration of cement particles more than other raw polymer superplasticizers. In addition, thermal stimulation improves the dispersibility of the cement particles, lowering their stiffness since it further reduces their cohesion. Therefore, thermal stimulation is thought to improve the dispersibility of the cement particles, making it more difficult for the particles to aggregate and thus avoiding stiffness. Therefore, thermal stimulation has the effect of improving and maintaining the mortar's fluidity, reducing its stiffness. These results indicate that thermal stimulation, produced by simply heating superplasticizers, can improve construction performance.

\subsection{Effect of Thermal Stimulation of Superplasticizers on Fresh Properties of Mortar with Vibration}

Figures 14 and 15 show changes in plastic viscosity and flow under vibration for the two types of heat-stimulated superplasticizers. Figure 14 shows that fluidity improved under thermal stimulation with and without vibration, while Fig. 15 confirms that the plastic viscosity of the mortar was reduced by thermally stimulating the superplasticizers. This reduction was about $17 \%$ for the PCa-type and about $40 \%$ for the RMC-type superplasticizer, indicating that thermally stimulating the RMC superplasticizer is more effective in improving its ability to reduce plastic viscosity and increase fluidity.

This is related to the fact that thermally stimulating the superplasticizer increased its apparent polymer size and improved flowability, as shown in previous studies (Takigawa et al. 2018, 2019). The apparent size of the polymer described in previous studies is based on the polymer 


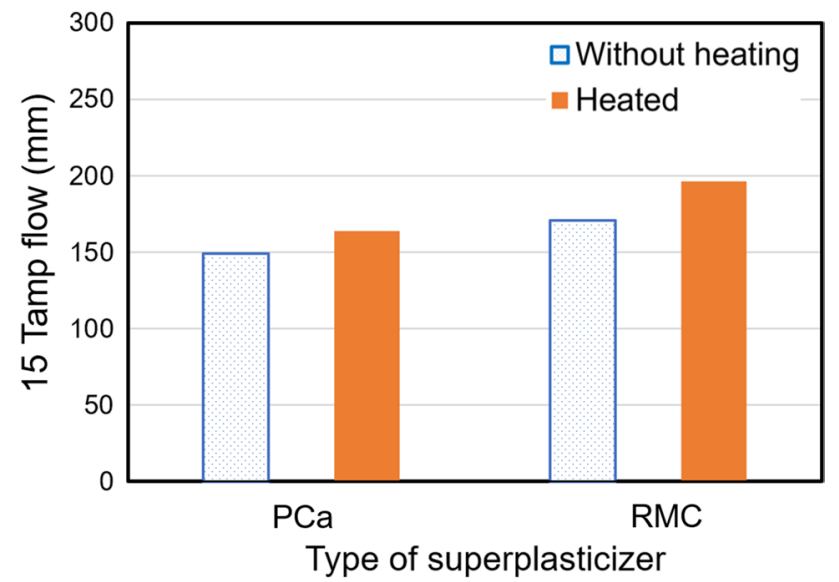

Fig. 14 Changes in flow due to thermal stimulation for two types of superplasticizers under vibration

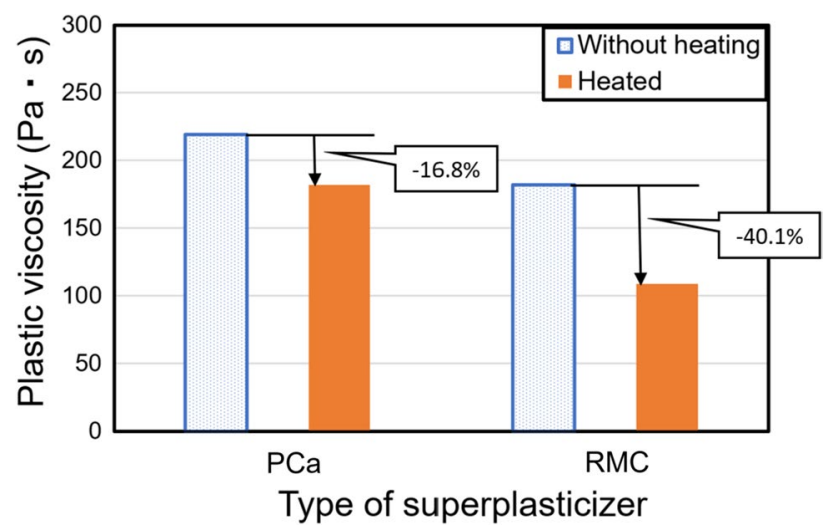

Fig. 15 Changes in plastic viscosity due to thermal stimulation for two types of superplasticizers under vibration

structure. Flowability and workability are affected by the length of the main and side chains of the polymer (Qianping et al. 2009; Sakai et al. 2003; Özen et al. 2020). Moreover, for polymers with ethylene oxide chains, such as those contained in polycarboxylic acid superplasticizers, it has been confirmed that cement particles have more difficulty agglomerating and causing slump loss if the side chains are longer and the density of the side chains is higher than that of the main chains (Ohta 1997; Sugiyama et al. 2000; Ran et al. 2009). It has also been reported that the rheological properties of mortars with polycarboxylic acid superplasticizers having short side chains improved as the length of the side chains increased (Andreas and Frank 2007; Hamada et al. 2006). In light of the hypotheses made in previous studies, it can be inferred that the polymers in superplasticizers that retain slump performance well have long side chains that tend to become entangled, but thermal stimulation causes the entangled polymers to unravel, which not

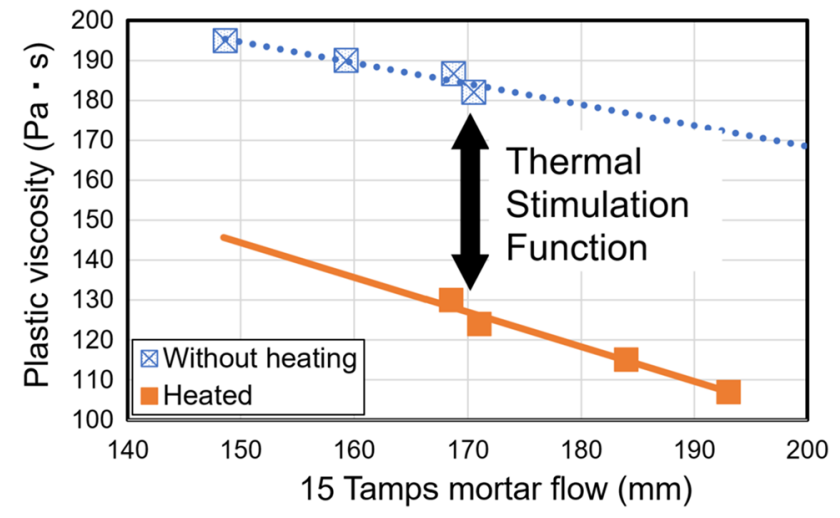

Fig. 16 Relationship between the changes in flow and plastic viscosity in RMC-type with vibration

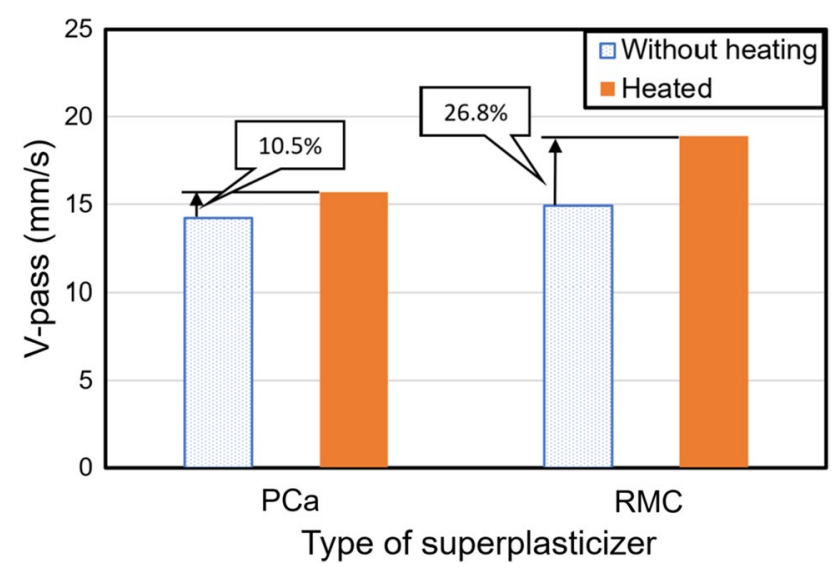

Fig. 17 Changes in V-pass due to thermal stimulation

only improves flowability but also affects plastic viscosity (Takigawa et al. 2018, 2019).

Figure 16 shows the relationship between changes in flow and plastic viscosity for the RMC-type plasticizer with vibration. Generally, the plastic viscosity of mortar tends to decrease as flow increases ( $\fallingdotseq$ the yield value decreases). The figure shows the data both with and without thermal stimulation to have linear relationships, as shown in a previous study (Hamada et al. 2006) but also indicates that they do not follow the same straight line. From this, it is inferred that reducing plastic viscosity by thermal stimulation not only increases flow but also reduces plastic viscosity. The authors would like to clarify this mechanism as a future task. Figures 17 and 18 show the change in V-pass due to thermal stimulation and the relationship between plastic viscosity and fluidity with vibration by plasticizer type. No significant material separation, such as bleeding, was confirmed in the experimental conditions of this study. Figures 17 and 18 show that thermal stimulation increased V-pass by about $10 \%$ for the PCa-type and about $27 \%$ for the RMC-type. 


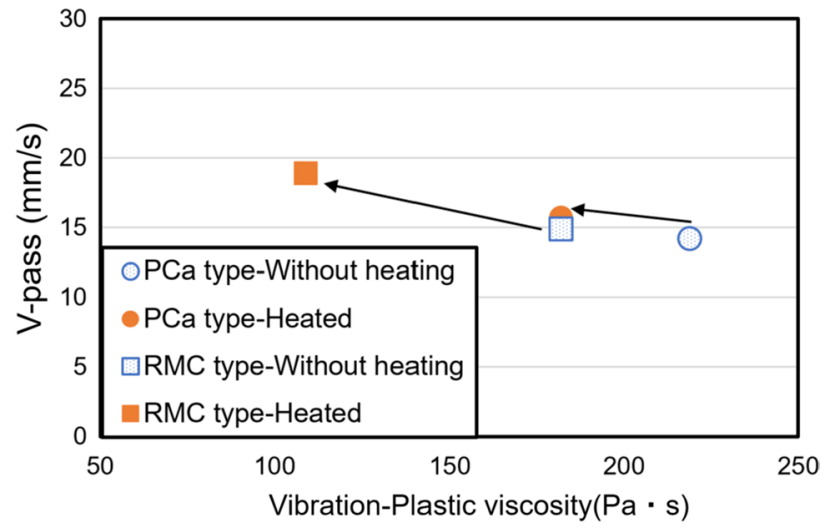

Fig. 18 Relationship between plastic viscosity and fluidity with vibration

This indicates that the faster the V-pass, the smaller the plastic viscosity with vibration. These results confirm that thermal stimulation improved the fluidity of the mortar using polycarboxylic acid ether-based superplasticizers. They also confirmed that plastic viscosity decreased and that filling performance improved.

Even with the same flow, the mortar's plastic viscosity using thermally stimulated superplasticizers is lower, indicating that thermal stimulation can be expected to improve construction performance. Phenomena such as underfill and blocking are less likely to occur, and their effects on the concrete's curing characteristics are also reduced. Therefore, the use of thermal stimulation of superplasticizers can be expected to improve workability because of the longer slump life, reduced plastic viscosity, and improved filling performance that they promote. However, in this study, the mechanism by which thermal stimulation decreases plastic viscosity has not been clearly elucidated, and the length of time the effects last has not been investigated, and further verification is necessary. In addition, assuming application to actual machines, verification of the relationship between various heating methods and heating conditions on the effect of thermal stimulation remains as a future topic for investigation.

\section{Conclusions}

The following findings were obtained by evaluating the effects of thermally stimulated superplasticizers on the characteristics of fresh mortar and its filling performance with and without vibration.

(1) Thermal stimulation reduces both plastic viscosity and mortar stiffness without vibration. This is presumed to be because the cement particles are less likely to aggregate when the superplasticizer is thermally stimulated.

(2) Filling performance is expected to improve because thermal stimulation causes plastic viscosity to decrease when vibration is applied and because of V-pass increases.

(3) RMC-type superplasticizers are more affected by thermal stimulation than PCa-type superplasticizers with regard to improving fluidity and reducing plastic viscosity.

Previous studies have confirmed that the performance of concrete is affected by the dosage and type of superplasticizer and its fresh and hardening properties. However, the most important point of this study is that construction performance was improved by thermally stimulating superplasticizers even if the dosage and type were constant and that the effectiveness depended on the type of superplasticizer even when the material was thermally stimulated in the same manner. This result is new, not having been found in previous studies. In addition, this work indicates that smaller amounts of superplasticizers can be used at construction sites and when making precast concrete products if the superplasticizers are thermally stimulated. Currently, the birthrate is declining, and with that, the aging population and turnover rate of skilled workers are increasing. Since this technology could be easily put into practical use by anyone, even a few laborers could improve productivity by using these research results at construction sites and reduce construction costs.

In the future, how thermal stimulation affects polymer molecules' adsorption efficiency on cement should be investigated to elucidate the full-scale mechanism and propose ways to adopt thermal stimulation at actual construction sites.

Acknowledgements We are grateful to Professor Rio Kita and Associate Professor Kaito Sasaki of Tokai University for helpful discussions about the polymer structure of superplasticizers and express our sincere thanks to them.

Funding No funds, grants, or other support were received.

Availability of data and material Takigawa M., Rahmanzai F., Kita R., Date S.: Basic Research of Improving the Mortar Flow by Thermal Stimulation to Superplasticizer, MATEC Web of Conferences, 278, 01003, pp. 1-6, 2018 https://doi.org/10.1051/matecconf/2019278010 03. Takigawa M., Bomura Y., Hashimoto S., Date S.: Effect of Thermal Stimulation on Various Characteristics of Superplasticizer, International Journal of Engineering and Technology, Vol. 11, No. 4, pp. 262-266, 2019 https://doi.org/10.7763/JJET.2019.V11.1158.

\section{Declarations}

Conflict of interest The authors declare that there is no conflict of interest regarding the publication of this paper. 
Open Access This article is licensed under a Creative Commons Attribution 4.0 International License, which permits use, sharing, adaptation, distribution and reproduction in any medium or format, as long as you give appropriate credit to the original author(s) and the source, provide a link to the Creative Commons licence, and indicate if changes were made. The images or other third party material in this article are included in the article's Creative Commons licence, unless indicated otherwise in a credit line to the material. If material is not included in the article's Creative Commons licence and your intended use is not permitted by statutory regulation or exceeds the permitted use, you will need to obtain permission directly from the copyright holder. To view a copy of this licence, visit http://creativecommons.org/licenses/by/4.0/.

\section{References}

Andreas L, Frank W (2007) The effect of viscosity modifying agents on mortar and concrete. Cem Concr Compos 29(5):341-349. https://doi.org/10.1016/j.cemconcomp.2007.01.004

Bache HH (1981) Densified cement-based ultrafine particle-based material. In: Proceedings of the 2 nd international conference on superplasticizer in concrete Ottawa, pp 185-213

Chandra S, Björnström J (2002) Influence of superplasticizer type and dosage on the slump loss of Portland cement mortarsPart II. Cem Concr Res 32:1613-1619. https://doi.org/10.1016/ S0008-8846(02)00838-4

Committee of Japanese Standards Association (2015) JIS Hand-Book No.10 Fresh Concrete. Tokyo, Japan

Fischer WE (1958) Elektronenmikroskopische Untersuchungen zur Stabilität von Suspensionen in makromolekularen Lösungen. Kollold-Zeltschrift 160(2):120-141. https://doi.org/10.1007/ BF01503288

Haga T, Aoki S, Miura N, Chikamatu R (1999) Basic research on ultra-high strength underground continuous wall concrete. In: The 46th annual scientific lecture meeting of the Japan Society of Civil Engineers V, pp 648-649 (Japanese)

Hamada D, Sato T, Yomoto F, Mizumura (2000) Development of new superplasticizer and its application to self-compacting concrete. In: Malhotra VM (ed) Proceedings of the 6th CANMET/ ACI international conference on superplasticizers and other chemical admixtures in concrete, vol 211. American Concrete Institute SP-195-17, pp 269-290

Hamada D, Hamai T, Shitada M, Shonaka M (2006) New high-performance water reducing agent pursuing workability of fresh concrete. Proc Jpn Concr Inst 28(1):185-190

Jacek GC, Janusz S (2004) Influence of superplasticizers on rheological behaviour of fresh cement mortar. Cem Concr Res 34:235-248

Jolicoeur C, Sharman J, Otis N, Lebel A, Simard MA, Page M (1997) The influence of temperature on the rheological properties of superplasticized cement pastes. In: 5th CANMET/ACI international conference on superplasticizers and other chemical admixtures in concrete, vol 173, pp 379-415

Kato H, Yoshioka K, Nakamura A (1999) Influence of temperature on the dispersion of cement particles by superplasticizers. Proce Jpn Concr Inst 21(2):163-168 (Japanese)

Kirby GH, Lewis JA (2008) Comb polymer architecture effects on the rheological property evolution of concentrated cement suspensions. J Am Ceram Soc 87(9):1643-1652. https://doi.org/ 10.1111/j.1551-2916.2004.01643.x

Lagaly G (1977) An introduction to clay colloid chemistry. By H van Olphen. Interscience Publishers, Div. of John Wiley \& Sons, 605 Third Ave., New York 16. J Pharm Sci 236-237. https:// doi.org/10.1002/jps.2600530238
Lucia F, Josef K, Frank W, Johann P (2010) Interaction of cement model systems with superplasticizers investigated by atomic force microscopy, zeta potential, and adsorption measurements. J Colloid Interface Sci 347:15-24. https://doi.org/10.1016/j.jcis. 2010.03.005

Lucia F, Josef K, Frank W, Johann P (2011) Multi-method approach to study influence of superplasticizers on cement suspensions. Cem Concr Res 41(10):1058-1066. https://doi.org/10.1016/j. cemconres.2011.06.010

Mackor LE (1951) A theoretical approach of the colloid-chemical stability of dispersions in hydrocarbons. J Colloid Science 6(5):492-495. https://doi.org/10.1016/0095-8522(51)90019-0

Mezger TG (2006) The rheology handbook, 2nd edn. Vincent Network, Hannover Coatings Compendia, Hanover

Morita Y, Ohta A (1994) The trend of air entraining and high range water reducing agent. J Soc Mater Sci 43(491):919-9294 (Japanese)

Muroga Y, Date S, Osuga T (2000) Development of mortar viscosity evaluation test equipment. In: Japan society of civil engineers annual academic lecture lecture summary part 5, vol 55, pp 814-815 (Japanese). https://doi.org/10.2208/jscej1949.1967. 138_39

Nemoto H, Hirano S, Hashimoto S, Date S (2020) Experimental verification of chemical admixture to reduce stiffness of concrete. Kye Eng Mater 853:198-208

Ohta A (1997) Fluidizing mechanism and application of polycarboxylate-based superplasticizers. In: 5th CANMET/ACI international conference on superplasticizers and other chemical admixtures in concrete, pp 359-378

Ohta A (2005) Polymer dispersants currently used in civil engineering and architectural field. J Soc Inorg Mater 12:448-454 (Japanese)

Ohta A, Uomoto T (1997) Fundamental study on the chemical structures of advanced superplasticizers and their effect on flowability (1). Seisan Kenkyu 49(12):637-640 (Japanese)

Ohtsuka Y, Atarashi D, Miyauchi M, Etsuo Sakai E (2015) Action mechanism of superplasticizer in consideration of early hydration of cement. J Adv Concr Technol 13:373-378

Özen S, Altun GM, Mardani A, Ramyar K (2020) Effect of main and side chain length change of polycarboxylate-ether-based waterreducing admixtures on the fresh state and mechanical properties of cementitious systems. Struct Concr. https://doi.org/10.1002/ suco. 201900489

Papayianni I, Tsohos G, Oikonomou N, Mavria P (2005) Influence of superplasticizer type and mix design parameters on the performance of them in concrete mixtures. Cem Concr Compos 27(2):217-222. https://doi.org/10.1016/j.cemconcomp.2004.02. 010

Petit JY, Wirquin E, Duthoit B (2005) Influence of temperature on the yield value of highly flowable micromortars made with sulfonatebased superplasticizer. Cem Concr Res 35(2):256-266. https://doi. org/10.1016/j.cemconres.2004.04.025

Qianping R, Ponisseril S, Changwen M, Jiaping L, Shishan W, Jian $S$ (2009) Effect of the length of the side chains of comb-like copolymer dispersants on dispersion and rheological properties of concentrated cement suspensions. J Colloid Interface Sci 336(2):624-633. https://doi.org/10.1016/j.jcis.2009.04.057

Ran Q, Liu J, Changwen M, Yan S, Yonglin M (2009) Effect of the side chain length of comb-like copolymer superplasticizer on early hydration properties of concentrated cement suspensions. J Colloid Interface Sci 336(2):624-633

Robert JF (2004) Dispersion forces in cement suspensions. Cem Concr Res 39:399-408. https://doi.org/10.1016/j.cemconres.2003.08.019

Robert JF, Joerg Z, Hampel C, Kurz C, Schober I, Frunz L, Plassard C, Lesniewska E (2009) The role of adsorption energy in the sulfatepolycarboxylate competition. ACI Int Conf 262:153-164 
Sakai E, Yamada K, Ohta A (2003) Molecular structure and dispersionadsorption mechanisms of comb-type superplasticizers used in Japan. J Adv Concr Technol 1(1):16-25. https://doi.org/10.3151/ jact.1.16

Shibata T (1967) on the shear strength of normally-consolidated clay measured in vane tests. Trans Jpn Soc Civ Eng 1967(138):39-48 (Japanese)

Sugamata T, Hibino M, Ohuchi M, Okamura H (2000) Effects of the molecular structure of polycarboxylate polymers on the cement particle dispersibility. J JSCE V-49 (662):17-27 (Japanese)

Sugiyama T, Matsuo S, Ohta A (2000) Latest trends in polycarboxylate-based dispersant research. NMB Res Inst Bull (13):1-10 (Japanese)

Takehisa D, Ide I, Hashimoto S, Date S (2018) Study on improvement of vibration compaction performance of fresh mortar. Int J Struct Civ Eng Res 7(1):40-45

Takigawa M, Rahmanzai F, Kita R, Date S (2018) Basic research of improving the mortar flow by thermal stimulation to superplasticizer. In: MATEC web of conferences, vol 278, no 01003, pp 1-6
Takigawa M, Bomura Y, Hashimoto H, Date S (2019) Effect of thermal stimulation on various characteristics of superplasticizer. Int J Eng Technol 11(4):262-266

Tanaka Y, Matsuo S, Ohta A, Ueda M (1996) A new admixture for high-performance concrete, radical concrete technology. In: Proceedings of the concrete in the service of mankind, E\&FN Spon, London, pp 286-294

Uchikawa H, Hanehara S, Sawaki D (1997a) A reply to the discussion by Susanta Chatterji of the paper" the role of steric repulsive force in the dispersion of cement particles in fresh paste prepared with organic admixture". Cem Concr Res 27(9):1453-1455. https://doi. org/10.1016/S0008-8846(97)00132-4

Uchikawa H, Hanehara S, Sawaki D (1997b) The role of steric repulsive force in the dispersion of cement particles in fresh paste prepared with organic admixture. Cem Concr Res 27(1):37-50

Yamada K, Ogawa S, Hanehara S (2001) Controlling of the adsorption and dispersing force of polycarboxylate-type superplasticizer by sulfate ion concentration in aqueous phase. Cem Concr Res 31(3):375-383 